\title{
BIBECHANA
}

A Multidisciplinary Journal of Science, Technology and Mathematics

ISSN 2091-0762 (online)

Journal homepage: http://nepjol.info/index.php/BIBECHANA

\section{Molecular characterization of yohimbine hydrochloride using vibrational spectroscopy and quantum chemical calculations}

\author{
Bhawani Datt Joshi ${ }^{1,3}$, Poonam Tandon ${ }^{1, *}$ and Sudha Jain ${ }^{2}$ \\ ${ }^{1}$ Department of Physics, University of Lucknow, Lucknow-226007, India \\ ${ }^{2}$ Department of Chemistry, University of Lucknow, Lucknow-226007, India \\ ${ }^{3}$ Department of Physics, Siddhanath Sc. Campus, Mahendranagar, Tribhuvan University, Nepal \\ *Corresponding author. Tel.: +91 522 2782653; fax: +91522 2740840. \\ E-mail address: poonam tandon@yahoo.co.uk, poonam tandon@hotmail.com (P. Tandon) \\ Article history: Received 22 June, 2011; Accepted 20 August, 2011
}

\begin{abstract}
In this work, we have performed the extraction of yohimbine hydrochloride $\left(\mathrm{C}_{21} \mathrm{H}_{27} \mathrm{CIN}_{2} \mathrm{O}_{3}\right)(\mathrm{YHCl})$. The optimized geometry, total energy, potential energy surface and vibrational wavenumbers of $\mathrm{YHCl}$ have been determined by using $a b$ initio Hartree-Fock (HF) and density functional theory (DFT/B3LYP) method with 6-311++G(d,p) basis set. The calculated wavenumbers are scaled by a proper scaling factor. A selected number of vibrational assignment is provided for the observed Raman and IR spectra.
\end{abstract}

Keywords: YHCl; vibrational spectroscopy; ESP; ab initio and DFT calculations

\section{Introduction}

Yohimbine, an indole alkaloid is the active ingredient obtained from the bark of various tropical trees such as Pausinystalia yohimbe (formarly Corynanthe yohimbe), a tall evergreen tree indigenous to southern African countries, and from the Indian snake root Rauwolfia serpentina [1,2]. Yohimbine hydrochloride (17a - hydroxy -yohimbane 16a - carboxylic acid methyl ester hydrochloride), a standard form belongs to an orthorhombic system, probable space group $\mathrm{P} 2{ }_{1} 2{ }_{1} 2{ }_{1}$ having lattice parameters, $a=11.54 \AA, b=24.88 \AA, c=7.00 \AA$ and $z=4$ [2]. It has been known as an aphrodisiac compound [2,3] and used traditionally since before the last century, even in the crude form by the African natives, and promoted for erectile dysfunction, weight loss (by releasing norepinephrine and blocking alpha-2 receptors) and depression (by blocking an enzyme called monoamine oxidase) [4-6]. It is used in tablets, capsule and tincture form for increased serumtesterone levels, muscle growth and strength, weight-loss, reduce fatigue in AIDS patients and libido enhancer [7]. Also it has been reported as traditional medicine to treat high blood pressure, chest pain, age- related cognitive disorders and obesity [8].

As the literature survey reveals neither Raman and IR spectra nor quantum chemical calculations for $\mathrm{YHCl}$ molecule have been reported so far, hence the present work was undertaken to study the vibrational spectra with quantum chemical calculation with greater accuracy. Although X-ray diffraction method is one of the most frequently applied techniques for structural characterization of pharmaceutical compounds but the use of vibrational spectroscopy is also gaining increasing attention. X-ray diffraction techniques are sensible to the long-range order while vibrational spectroscopy (IR [9] and Raman [10]) is applicable to the short-range structure of molecular solids. 
Bhawani Datt Joshi et al./ BIBECHANA 8 (2012) 73-80 : BMHSS, p.74

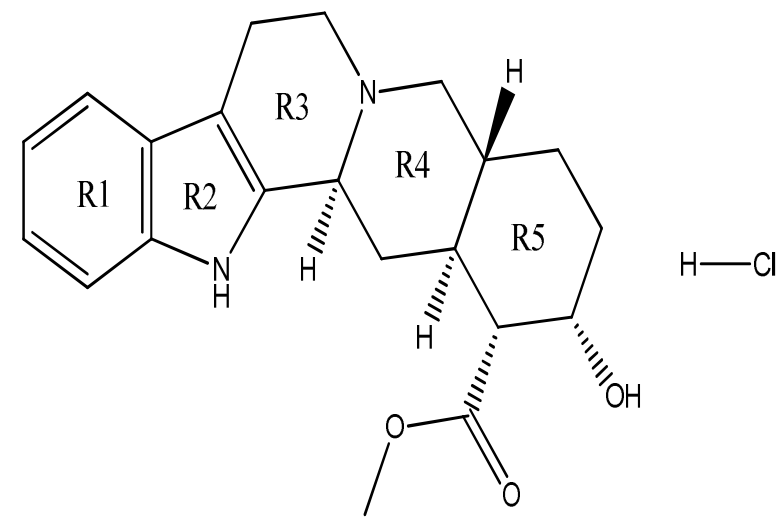

Fig. 1: Crystal structure of $\mathrm{YHCl}$.

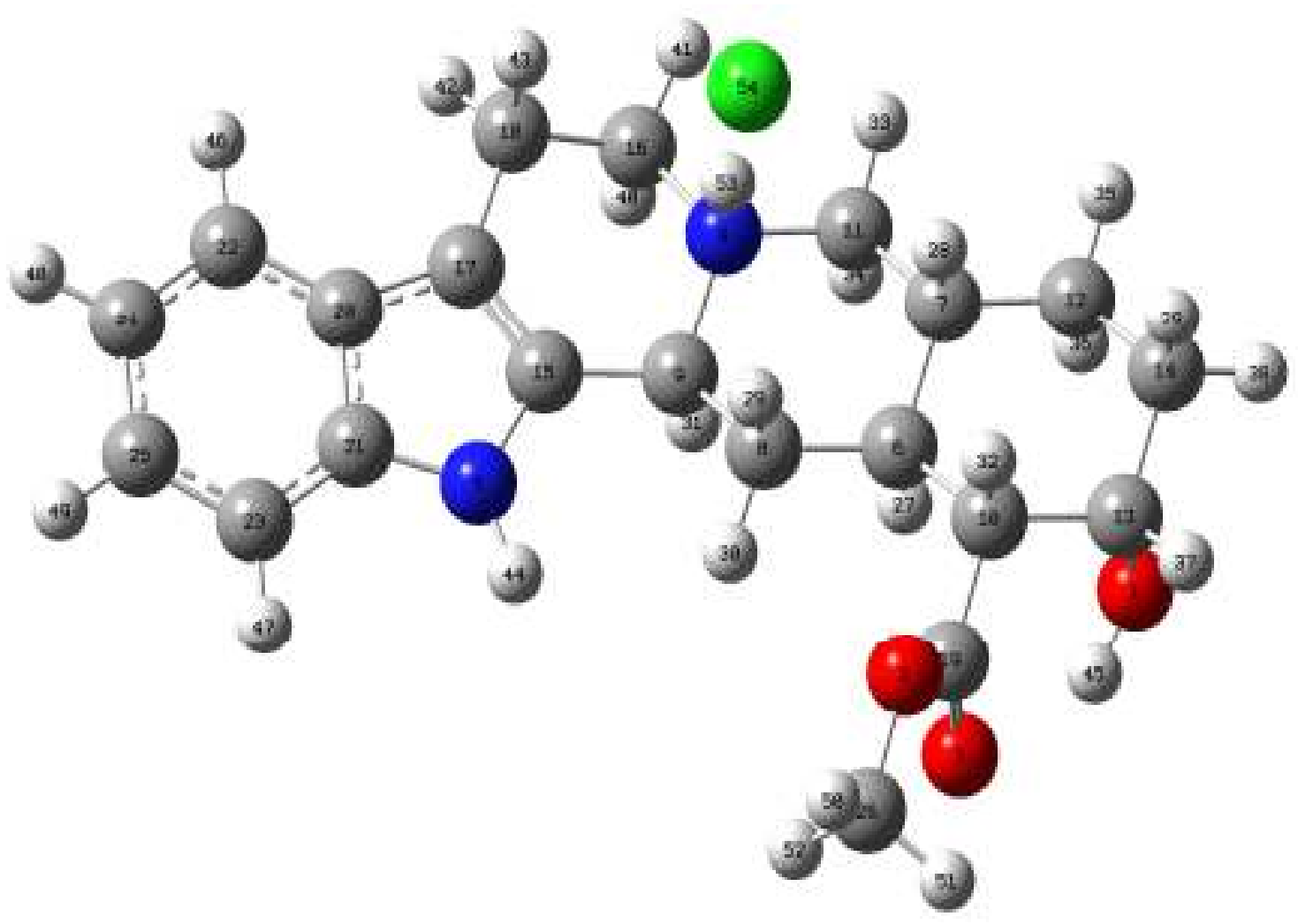

Fig. 2: Optimized structure of $\mathrm{YHCl}$. 
Furthermore, we interpreted the calculated spectra in terms of potential energy distributions (PED) and made the assignment of the experimental bands due to PED analysis results. Information about the geometry and structure of the molecule with their electrostatic potential surfaces should help in understanding the structure-activity relationship. Figure 1 shows the crystal structure of the $\mathrm{YHCl}$ molecule.

\section{Materials and Methods}

\subsection{Experimental Methods}

The whole plants of Rauwolfia serpentine Benth. (Apocynaceae) were collected from Lucknow, Uttar Pradesh, India and identified by the Botany Division of Central Drug Research Institute, Lucknow, India. The plant material $(2.4 \mathrm{Kg})$ was air-dried, powdered and percolated with ethyl alcohol $(6 \times 4 \mathrm{It})$ at room temperature. The combined percolate was concentrated under reduced pressure below $40^{\circ}$ to give the viscous mass. The material was partitioned between $2 \%$ tartaric acid and hexane. The aqueous solution was re-extracted with hexane $(4 \times 250 \mathrm{ml})$, basified with solid $\mathrm{Na}_{2} \mathrm{CO}_{3}(\mathrm{pH} 7.5)$ and extracted with benzene $(6 \times 250 \mathrm{ml})$. The combined benzene layer was dried over anhydrous $\mathrm{Na}_{2} \mathrm{SO}_{4}$ and solvent removed under reduced pressure to give a residue - I. The aqueous solution left after extraction with benzene was further extracted with methylene chloride $(5 \times 250 \mathrm{ml})$. The combined methylene chloride layer was dried over anhydrous $\mathrm{Na}_{2} \mathrm{SO}_{4}$ and solvent removed under reduced pressure to give a residue - II. Both the residues I and II were mixed to afford crude alkaloidal mixture $(4.0 \mathrm{~g})$ which was subjected to column chromatography over neutral alumina. The column was successively eluted with hexane, hexane: benzene (20:80), benzene, benzene - ethyl acetate, $\mathrm{v} / \mathrm{v}$ (98:2), (95:5), (90:10), (85:15), (50:50), (25:75), ethyl acetate, ethyl acetate-methanol (95:5) and methanol. Elution was monitored by thin layer chromatography (tlc). A total of 190 fractions, $100 \mathrm{ml}$ each, were collected and mixed on the basis of tlc. The fractions $42-75$ eluted from benzene-ethyl acetate (98:2), (95:5) and (90:10) were mixed and solvent removed. The crude product was subjected to preparative tlc (plates: $\mathrm{SiO}_{2} \mathrm{GF}_{254}$; solvent: chloroform - methanol, 95:5; double run). The major band on the plates was scraped, extracted with chloroform - methanol (3:1), the solvent removed under reduced pressure to give a pure compound $(8.4 \mathrm{mg})$, converted to its hydrochloride, crystallized from methanol - ether, m.p. $299.5^{0}\left[301^{0}\right][11,12]$. The compound was identified as yohimbine by a direct comparison with an authentic sample procured from Sigma Chemical Company, USA.

An excitation laser of wavelength $514 \mathrm{~nm}$ was emitted from an Argon ion laser source and a power of $12 \mathrm{~mW}$ was used to record the vibrational spectra using an efficient visible micro Raman setup at room temperature. The scattered Raman light was collected in a back scattering geometry using a microscope objective (ULW x50). The scattered light was dispersed using a monochromator with 1200 grooves $/ \mathrm{mm}$ diffraction grating, and an entrance slit width of 200 micrometer. The Raman signals were detected using liquid nitrogen cooled charged coupled device (CCD) with an optimal sensitivity in the visible range. The total exposure time for each sample was $5 \mathrm{sec}$ and averaged over five accumulations.

Infrared spectra of $\mathrm{YHCl}$ were recorded on a Bruker TENSOR $27 \mathrm{FT}$-IR spectrometer with a spectral resolution of $4 \mathrm{~cm}^{-1}$ in the region $300-4000 \mathrm{~cm}^{-1}$. The $\mathrm{KBr}$ pellets of solid samples were prepared from mixtures of $\mathrm{KBr}$ and the sample in 200:1 ratio using a hydraulic press. Multi-tasking OPUS software was used for base line corrections.

\subsection{Computational Methods}

Geometry optimization was performed as the first task of computational work for the $\mathrm{YHCl}$ molecule. The experimental geometric parameters from X-ray diffraction data [2] of $\mathrm{YHCl}$ molecule were used as the initial parameters for the theoretical calculations. The electronic structure and optimized geometry of the molecule were computed by ab initio Hartree-Fock (HF) and DFT (density functional 
theory) using Gaussian 09 [13] program package employing 6-311++G(d,p) basis set based on Becke's three-parameter (local, non-local, Hartree-Fock) hybrid exchange functional with Lee-YangParr correlation functional (B3LYP) [14]. The basis set $6-311++G(d, p)$ augmented by d polarization functions on heavy atoms and $p$ polarization functions on hydrogen atoms as well as diffuse functions for both hydrogen and heavy atoms were used. The optimized structural parameters were used to calculate the absolute Raman intensities and infrared absorption intensities in the harmonic approximation at the HF and DFT levels. The positive values of all the obtained 156 wavenumbers confirm the stability of optimized geometry. For analyzing the normal a complete set of 156 internal co-ordinates was defined using Pulay's recommendations [15]. The vibrational assignments of the normal modes were proposed on the basis of the PED calculated using the program GAR2PED [16]. Raman and infrared spectra were simulated using a pure Lorentzian band profile $\left(\mathrm{fwhm}=8 \mathrm{~cm}^{-1}\right.$ ) using indigenously developed software. Visualization and confirmation of the calculated forms of the vibrations were done using the CHEMCRAFT program [17].

\section{Geometry Optimization and Energies}

Initial geometry taken from the X-ray diffraction data [2] of $\mathrm{YHCl}$ was minimized without any constraint to the potential energy surface and the optimized structural parameters were used in the vibrational frequency calculation to characterize all stationary points as minima. The equilibrium geometry has been determined by the energy minimization. The optimized structure of $\mathrm{YHCl}$ molecule is shown in Figure 2. The relative energies of the molecule are calculated employing $a b$ initio HF and DFT functional (B3LYP). The DFT includes some electron correlation effects and hence the calculations with this method are better than the HF approach. The energy calculated by DFT $(-1612.2632515$ Hartree) is lower than the one calculated by HF (-1612.2607923 Hartree).

The optimized structural parameters (bond lengths, bond angles, dihedral angles) of YHCl have been compared with the experimental one. The difference between experimental and calculated values of bond-lengths is not more than $0.04 \AA$, both in DFT and HF methods. The bond angles differ by not more than $2.5^{\circ}$ except the angles, C19-O2-C26 and O1-C13-C10 which differ by $4.82^{\circ} / 5.82^{\circ}$ and $5.64^{\circ}$ $15.64^{\circ}$ in the DFT/HF respectively. Similarly the dihedral angles differ by not more than $4.9^{\circ}$ except the angles $\mathrm{C} 6-\mathrm{C} 10-\mathrm{C} 19-\mathrm{O} 2$ and $\mathrm{C} 6-\mathrm{C} 10-\mathrm{C} 19-\mathrm{O} 3$ differ by $6.83^{\circ} / 6.83^{\circ}$ and $6.34^{\circ} / 6.34^{\circ}$ in the DFT/HF respectively.

\section{Results and Discussion}

\subsection{Molecular Electrostatic Potential}

The molecular electrostatic potential (ESP) of a molecule at a point in space around it gives an indication of the net electrostatic effect produced by the total charge distribution (electrons + nuclei) of the molecule. The molecular ESP of $\mathrm{YHCl}$ molecule is shown in Figure 3. It correlates the total charge distribution with dipole moments, partial charges, electro-negativity and site of chemical reactivity of a molecule. ESP provides a visual method to understand the relative polarity of a molecule and serves as a useful quantity to explain hydrogen bonding, reactivity and structure-activity relationship of

molecules including biomolecules and drugs [18]. Different colours represent the different values of the electrostatic potential at the surface of a molecule. In general, red colour represents the regions of most negative electrostatic potential (possess electrophilic property), blue represents the regions of most positive electrostatic potential (possess nucleophilic property) and green represents the regions of zero potential. Potential increases in the order red $<$ orange $<$ yellow $<$ green $<$ blue.

The electrostatic potential has been used primarily for predicting sites and relative reactivities towards electrophilic attack and in studies of biological recognition and hydrogen bonding interactions [19]. In order to predict the reactive sites for electrophilic and nucleophilic attacks of the title molecule, such electrostatic potential surfaces have been plotted for molecules in $6-311++G(d, p)$ basis set using the computer software GAUSSVIEW ver.09 [14] as shown in Figure 3. In YHCl molecule, the regions near 


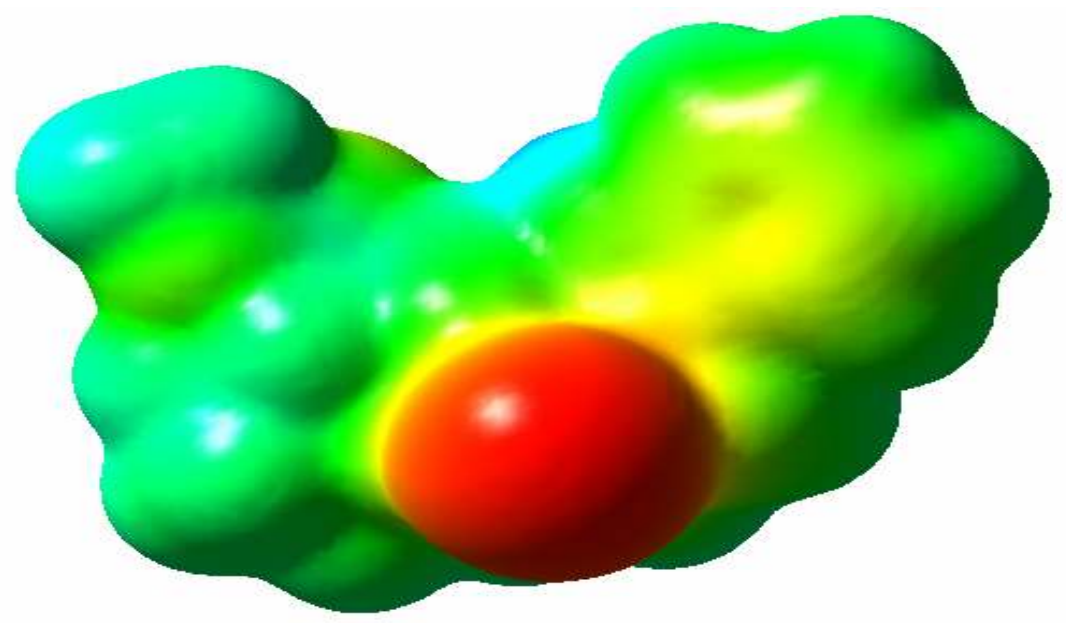

$7.3996 \cdot 2$

Fig. 3. Molecular electrostatic potential mapped on the isodensity surface in the range from $-7.390^{*} 10^{-}$ 2 (red) to $+7.390 * 10^{-2}$ (blue) for $\mathrm{YHCl}$.

the chlorine atom of hydrochloride groups as well as those of hydroxyl groups are most negative, while the regions near hydrogen of hydroxyl groups are the most positive regions.

\subsection{Vibrational Assignments}

The total number of atoms in a molecule is 54, hence gives $156(3 \mathrm{~N}-6)$ normal modes of vibrations. All the 156 fundamental vibrations of the YHCL molecule are both Raman and IR active. The vibrational spectrum is mainly determined by the modes of the free molecule observed at higher wavenumbers, together with the lattice (translational and vlibrational) modes in the low wavenumber region. All the vibrational bands have been assigned satisfactorily. The assigned wavenumbers of the selected vibrational modes calculated at the HF and B3LYP level with the basis set $6-311++G(d, p)$ along with their PED are given in Table.

Since the vibrational wavenumbers obtained from the DFT calculations are higher than the experimental wavenumbers, they were scaled down by the wavenumber linear scaling procedure $(\mathrm{WLS})\left[\mathrm{v}_{\mathrm{obs}} / \mathrm{v}_{\mathrm{cal}}=\left(1.0087-0.0000163 \times \mathrm{v}_{\text {cal }}\right) \mathrm{cm}^{-1}\right.$ ] of Yoshida et al. [20] and a comparison was made with the experimental values. However there are different scaling factors, but the vibrational wavenumbers calculated uniformly scaled with only one scaling factor [21] are often in good agreement the observed ones. All the calculated vibrational wavenumbers reported in this study are the scaled values.

In the ring $\mathrm{R} 1$, the $\mathrm{CH}$ stretching of the ring is calculated in the region $3052-3027 \mathrm{~cm}^{-1}$ and match well with the values $3057,3031 \mathrm{~cm}^{-1}$ in the Raman and 3087 and $3066 \mathrm{~cm}^{-1}$ in the IR spectra. The in-plane deformations of $\mathrm{CH}$ group are calculated to be 1453,1384 and $1238 \mathrm{~cm}^{-1}$ and reported at 1452,1383 and $1245 \mathrm{~cm}^{-1}$ in the Raman and at 1452 and $1234 \mathrm{~cm}^{-1}$ in the IR spectrum, respectively.

In the ring $\mathrm{R} 2$, the $\mathrm{N} 5 \mathrm{H}$ stretching vibration is calculated to be $3481 \mathrm{~cm}^{-1}$ and observed as high intense peak at $3514 \mathrm{~cm}^{-1}$ in the IR spectrum as shown in the Figure 4.

In the ring $\mathrm{R} 3$, weak asymmetric stretching mode of $\mathrm{C}_{11} \mathrm{H}_{2}$ is calculated at $2972 \mathrm{~cm}^{-1}$ and assigned to the peak at $2965 \mathrm{~cm}^{-1}$ in the Raman and $2960 \mathrm{~cm}^{-1}$ in the IR spectrum. Symmetric stretching vibration 
Bhawani Datt Joshi et al./ BIBECHANA 8 (2012) 73-80 : BMHSS, p.78

Table: Some selected calculated and experimental wavenumbers $\left(\mathrm{cm}^{-1}\right)$ of $\mathrm{YHCl}$.

\begin{tabular}{|c|c|c|c|c|c|}
\hline Unscaled & \multicolumn{2}{|c|}{ Scaled } & \multirow[t]{2}{*}{ Raman } & \multirow[t]{2}{*}{ IR } & \multirow[t]{2}{*}{ Potential energy distribution } \\
\hline DFT & $\mathrm{HF}$ & DFT & & & \\
\hline 3838 & 3631 & 3631 & - & 3670 & $\mathrm{O} 1 \mathrm{H}$ - stretching \\
\hline 3669 & 3481 & 3481 & - & 3514 & $\mathrm{~N} 5 \mathrm{H}$ - stretching \\
\hline 3190 & 3052 & 3052 & 3057 & 3087 & $\mathrm{CH}$ - stretching \\
\hline 3179 & 3042 & 3042 & - & 3066 & $\mathrm{CH}$ - stretching \\
\hline 3169 & 3033 & 3033 & 3031 & - & $\mathrm{CH}$ - stretching \\
\hline 3163 & 3027 & 3027 & - & - & $\mathrm{CH}$ - stretching \\
\hline 3158 & 3023 & 3023 & - & 3024 & $\mathrm{CH}_{3}-$ asym stretching \\
\hline 3125 & 2993 & 2993 & 2989 & - & $\mathrm{CH}_{3}-$ asym stretching \\
\hline 3102 & 2972 & 2972 & 2965 & 2960 & $\mathrm{C}_{11} \mathrm{H}_{2}$-asym stretching \\
\hline 3052 & 2927 & 2927 & - & 2935 & $\mathrm{CH}_{3}-$ sym stretching \\
\hline 3034 & 2910 & 2910 & 2911 & - & $\mathrm{C} 11 \mathrm{H}_{2}-$ sym stretching \\
\hline 3017 & 2895 & 2895 & 2894 & 2887 & $(\mathrm{C} 6 \mathrm{H}+\mathrm{C} 7 \mathrm{H})-$ stretching \\
\hline 3006 & 2885 & 2885 & 2876 & 2883 & $(\mathrm{C} 7 \mathrm{H}+\mathrm{C} 6 \mathrm{H})-$ stretching \\
\hline 1785 & 1748 & 1748 & 1754 & 1718 & $\mathrm{C}=\mathrm{O}-$ stretching \\
\hline 1478 & 1455 & 1456 & 1453 & 1454 & $\mathrm{C} 18 \mathrm{H} 2$ - deformation \\
\hline 1476 & 1453 & 1453 & 1452 & 1452 & $\mathrm{CH}$ - in-plane deformation \\
\hline 1424 & 1403 & 1403 & 1408 & 1408 & HC1301 - deformation \\
\hline 1403 & 1384 & 1384 & 1383 & - & $\mathrm{CH}$ - in-plane deformation \\
\hline 1253 & 1238 & 1238 & 1245 & 1234 & $\mathrm{CH}$ - in-plane deformation \\
\hline 1176 & 1163 & 1163 & 1165 & - & C13O1H45 - deformation \\
\hline
\end{tabular}

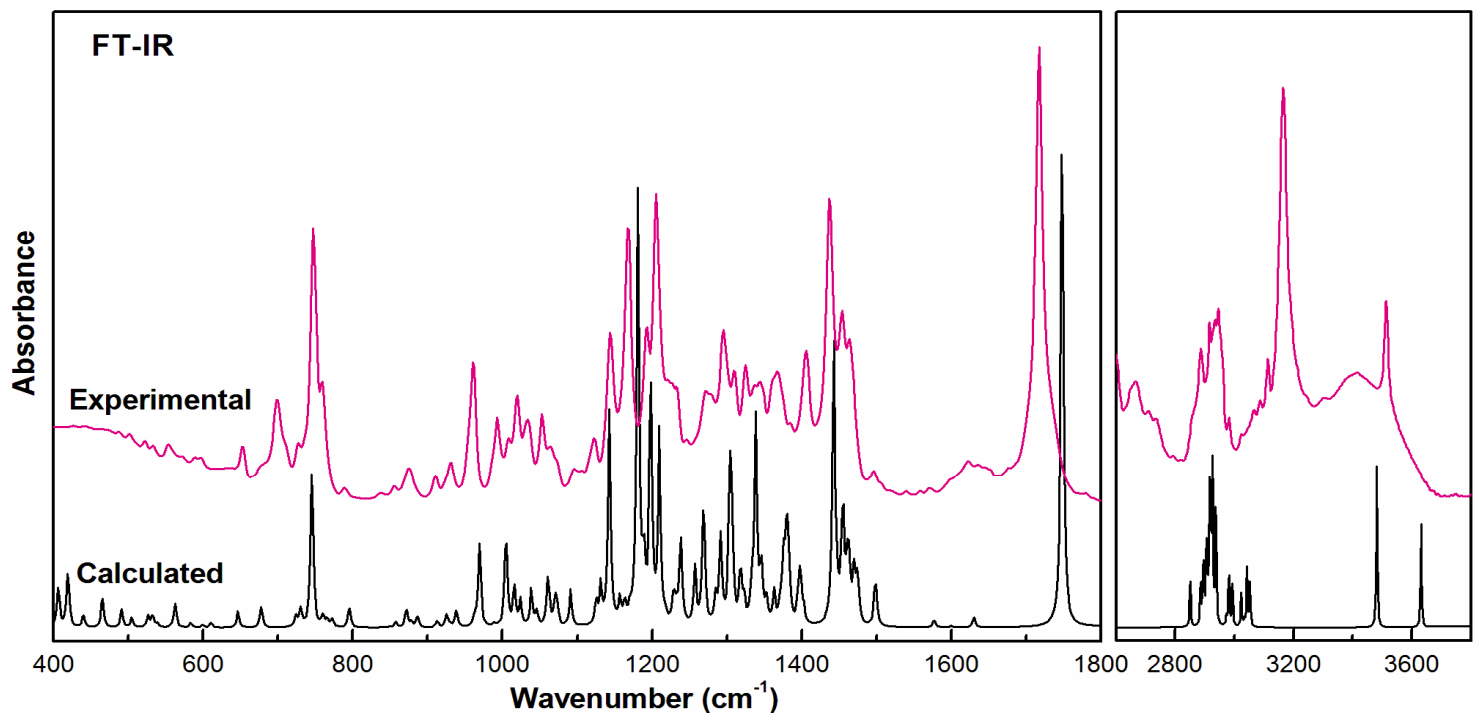

Fig. 4: Experimental and calculated (scaled) IR absorption spectra of $\mathrm{YHCl}$ in the Region $400-1800$ and $2600-3800 \mathrm{~cm}^{-1}$ 
of this mode is calculated to be $2910 \mathrm{~cm}^{-1}$ and reported at $2911 \mathrm{~cm}^{-1}$ in the Raman spectrum. The mixed vibrations of $\mathrm{C} 7 \mathrm{H}$ and $\mathrm{C} 6 \mathrm{H}$ stretching modes are calculated to be $2885 / 2895 \mathrm{~cm}^{-1}$ and observed at $2876 / 2894 \mathrm{~cm}^{-1}$ in the Raman and at $2883 / 2887 \mathrm{~cm}^{-1}$ in the IR spectrum, which match well with the experimental results.

In the ring R4, the stretching vibration of alcoholic $01 \mathrm{H}$ group is calculated at $3631 \mathrm{~cm}^{-1}$ and observed to the weak band in the IR spectrum at $3670 \mathrm{~cm}^{-1}$. The $\mathrm{O} 1 \mathrm{H}$ deformations are calculated to be $1403 / 1163 \mathrm{~cm}^{-1}$ and reported at $1408 / 1165 \mathrm{~cm}^{-1}$ with very weak band in the Raman and at $1408 \mathrm{~cm}^{-1}$ with a strong band in the IR spectrum.

The asymmetric stretches of $\mathrm{CH}_{3}$ group are calculated to be 3023 and $2993 \mathrm{~cm}^{-1}$ and reported at 2989 $\mathrm{cm}^{-1}$ with strong intensity in the Raman and with weak intensity at $3024 \mathrm{~cm}^{-1}$ in the IR spectrum. The $\mathrm{CH}_{3}$ symmetric stretching is calculated to be $2927 \mathrm{~cm}^{-1}$ and reported at $2935 \mathrm{~cm}^{-1}$ with medium intensity in the IR spectrum. High contributions of $\mathrm{C}=\mathrm{O}$ stretching band is calculated to be at $1748 \mathrm{~cm}$ ${ }^{1}$ and match nicely to the peak at $1719 \mathrm{~cm}^{-1}$ with weak intensity in the Raman and with strong intensity at $1718 \mathrm{~cm}^{-1}$ in the IR spectrum. This multiple bonded group is highly polar, therefore, gives rise to an intense IR band.

\section{Conclusions}

In this work, we have performed the experimental and theoretical vibrational and electrostatic potential surface analysis of the $\mathrm{YHCl}$. These assignments are important to understand the molecular structure and biological activity of the title molecule. The equilibrium geometries and harmonic vibrational wavenumbers of all the 156 normal modes of the molecule were determined and analyzed both at DFT and HF levels of theory employing the $6-311++G(d, p)$ basis set. Information about the size, shape, charge density distribution and structure-activity relationship of the $\mathrm{YHCl}$ molecule has been obtained by mapping electron density isosurface with ESP. Raman and infrared spectra were recorded, and the vibrational bands were assigned on the basis of the PED obtained from the DFT calculations.

\section{Acknowledgements}

The authors are grateful to the University Grants Commission, Nepal and, Alexander von Humboltd Foundation, Germany for providing partial financial assistance.

\section{References}

[1] A.E. El Gindy, M. Farouk, L. Abd El Aziz and E.S. Shokry, J. Appl. Sciences Research 5 (2009) 693.

[2] G. Ambady and G. Karth, J. Crist. Mol. Struct. 3 (1973) 37.

[3] AO Eweka, FAE Om'Iniabohs and O. Momodu, Biology and Medicine 2 (2010) 30.

[4] S. Lal, J.X. Thavundayil, B. Krishnan, N.P.V. Nair, G. Schwartz and H. Guyda, J. Physchiatry Neurosci. 21 (1996) 96.

[5] M.R. Goldberg and D. Robertson, Pharmcol Rev. 35 (1983) 143.

[6] R.M. Quinton, Brit. J. Pharmacol. 21 (1963) 51.

[7] J. S. James, AIDS Treatment News, 18 September 1992.

[8] J.Tank, K. Heusser, A. Diedrich, et al. Yohimbine Attenuates Baroreflex Mediated Bradycardia in Human. Hypertension. Nov, 50 (2007)899. Epub. Sept. 17, 2007.

[9] Crupi, D. Majolino, M.R. Mondello, P. Migliardo, and V. Venuti, J. Pharm. Biomed. Anal. 29 (2002) 1149.

[10] G. Fini, J. Raman spectroscopy. 35 (2004) 335.

[11] K. Warnat, Ber. (1930) 2959.

[12] G.A. Swan, J Chem. Soc. (1950) 1534. 
[13] M.J. Frisch, G.W. Trucks, H.B. Schlegel. G.E. Scuseria, J.R. Cheeseman, M.A. Robb, G. Scalmani, V. Barone, B. Mennucci, G.A. Petersson, H. Nakatsuji, M. Caricato, X. Li, H.P. Hratchian, A.F. Izmzylov, J. Bloino, G. Zheng, J.L. Sonnenberg, M. Hada, M. Ehara, K. Toyota, R. Fukuda, J. Ishida, M. Hasegawa, T. Nakajima, Y. Honda, O. Kitao, H. Nakai, T. Vreven, J.A. Montgomery, Jr., J.E. Peralta, F. Ogliaro, M. Bearpark, J.J. Heyd, E. Brothers, K.N. Kudin, V.N. Staroverov, R. Kobayashi, J. Normand, A. Raghavachari, A. Rendell, J.C. Burant, S.S. lyengar, J. Tomasi, M. Cossi, N. Rega, J.M. M illan, M. Klene, J.E. Knox, J.B. Cross, V. Bakken, C. Adamo, J. Jaramillo, R. Gomperts, R.E. Stratmann, O. Yazyev, A.J. Austin, R. Cammi, C. Pomelli, J.W. Ochterski, R.L. Martin, K. Morokuma, V.G. Zakrzewski, G.A. Voth, P. Salvador, J.J. Dannerberg, S. Dapprich, A.D. Daniels, J. Farkas, B. Foresman, J.V. Ortiz, J. Cioslowski. D.J. Fox, GAUSSIAN 09, Revision, (Gaussian, Inc., Wallingford CT, 2009).

[14] C.T. Lee, W.T. Yang and R. G. Parr, Phys. Rev. B 37 (1998) 785.

[15] P. Pulay, G. Fogarasi, F. Pang and J.E. Boggs, J. Am. Chem. Soc. 101 (1979) 2550.

[16] M.L. Martin and C Van Aslenoy, Gar2ped. University of Antwerp. 1995.

[17] E. Scrocco and J. Tomasi, Adv. Quantum Chem., 11 (1978) 115.

[18] T. Ashida, R. Repinsky and Y. Okaya, Acta Cryst. A.16 (1963) 48.

[19] C. Muñoz-Caro, A. Niño, M.L. Sement, J.M. Leal and S. Ibeas, J. Org. Chem. 65 (2000) 405.

[20] H. Yoshida, K. Takeda, J. Okamura, A. Ehara, and H. Matsurra, J. Phys. Chem. A 106 (2002) 3580.

[21] A.P. Scott and L. Radom, J. Phys. Chem. 100 (1996) 16502. 